\title{
Artistic Expression of Charm in Vocal Singing
}

\author{
Jiang Shanshan \\ Heihe College, Heihe Heilongjiang 164300
}

Keywords: Charm and beauty; Vocal music; Artistic expression

\begin{abstract}
Vocal music singing, as the mainstream art form of modern society, can bring aesthetic enjoyment to people's spiritual life. In vocal music singing, the use and performance of timbre have a very important impact on the overall expression of vocal music singing. This paper aims to explore the use and performance of silver in vocal music singing. As the main part of Chinese vocal music art, national vocal music is also the artistic essence of national artistic feelings, with unique national characteristics and aesthetic style and spirit, and the "charm beauty" embodies a unique aesthetic style, in vocal music singing by all ethnic music learners and researchers in favor of the academic community. In this paper, the content analysis method is mainly used to analyze the typical national vocal music examples, respectively, from the vocal music aesthetics in the "rhyme" and "emotional rhyme" of the artistic expression of "charm beauty" in national vocal music singing, deepening the "charm" beauty in national vocal music singing.
\end{abstract}

\section{Introduction}

China's national vocal music is mainly based on the local languages of various nationalities in various parts of the country. When singing in the line tune, the singing principle is usually the combination of words, rhyme and emotion. It reflects the brilliance of the blend of the three, and shows the aesthetic of national vocal music incisively and vividly. The beauty of "charm" is highly displayed in the traditional aesthetics of national vocal music in China. It involves vocal art such as rap, folk song and opera, and shows "charm" in the pursuit of artistic aesthetics. By quoting the typical songs "My China", opera "White Haired Girl" and Beijing opera "Dujuanshan Home in Anyuan", this paper combines the vocal rhyme, character rhyme and emotional rhyme of Chinese national vocal music to show the "charm beauty" of national vocal music art, which is of great practical significance to the aesthetic appreciation and appreciation of vocal music singing art. In recent years, due to the diversified development of music, vocal music singing has received widespread attention. In vocal music singing, the use and performance of timbre can better express the emotion that the song needs to convey. Based on this, the author has carried on the profound understanding of the concept of timbre and the application and performance of timbre in vocal music singing. We hope to provide some suggestions for the development of vocal music in China.

\section{The Charm of Sound}

"Sound" occupies an important position in the art of national vocal music. The "charm beauty" of 
voice is mainly manifested in the connection between "character" and "sound", extending under the blend of "character" and "sound", and controlling the singing situation with tactful singing skills. The requirement of "character" and "sound" in national vocal music art lies in that "character" emphasizes "sound" while "sound" is light, and "word" carries "sound", "word" and "sound" flow, so that the national vocal music art characters are square and round, and bel canto conveys meaning. As a national vocal singer, in the process of singing, we need to fully combine the changes of the melody, rhythm, sound area and speed of the vocal music art, combined with the singing skills of the national vocal music, to achieve the artistic beauty of the orthographic and round tone in the line, and to highlight the "charm beauty" of the national vocal music art. Singer Wang Zhe's "My China" in the lyrics "5,000 years cast into a Chinese" melody at the beginning of the melody " 3 " before the addition of a "5" accent, the lyrics "browse the history of youth" melody "332" will be "3" beautifully modified, embellished as the upper wave, the lyrics "Question the sky" melody "5" and the back accent "65" combination, through the decoration of notes to highlight the enthusiasm for the motherland, in line with the performance of different timbre changes and aesthetic taste, especially in the singer's aria timbre stirred the strings of life, in interesting to show unspeakable timbre beauty, subtly highlighted the national vocal music singing in the " Charm of charm.

In this paper, the author will discuss the tone color, mainly refers to the shade and soft and hard vibration of the sound, in fact, all the sound is produced by vibration, therefore, different sounds have different tone color, in vocal music singing, tone color contains a very wide range of content, such as pitch, volume, pitch, extensive. These belong to the category of timbre. The so-called pitch is the lowest frequency sound produced by an object in vibration, and all timbres except the pitch can be collectively called overtones. In addition, it is worth noting that timbre covers a wide range of areas, and the formation of timbre and timbre quality, length and the emotions of the sound have. This shows that the use and performance of timbre in vocal music singing is very complex, timbre can also directly determine the emotional expression and emotional transmission of vocal music singing.

\section{The Charm of the Word "Charm"}

The charm of Chinese characters in Chinese national vocal music is embodied in the charm of pronunciation, which is inherited from the traditional national vocal music. The charm of Chinese characters enriches the aesthetic taste of Chinese contemporary national vocal music to a certain extent. The so-called "charm beauty" of Chinese characters lies in the charm of pronunciation and pronunciation, and the charm of Chinese characters has certain standards. It is necessary to display the charm beauty of Chinese characters in accordance with the rules, requirements, styles, systems, the beginning, the end, the four hoots and the clear turbidity of the language, so that the singers and appreciators of national vocal music can clearly understand the artistic lyrics of the national vocal music. The deep meaning of "Zi" in music. Of course, the "charm" of characters and the "charm" of sounds in national vocal music should be combined. Because of the flexible use of "words" in the singing of national vocal music, the charm of "words" is usually displayed in the lyrics, and the collocation and use of words is also the essence of the composers of music lyrics. For example, singer Peng $\mathrm{Li}$ "Hatred is the key word" in the opera "White-haired Girl" singing "Hatred is mountain hatred is sea", the singer will "hate" music emotion through the melting cavity will "hate" emotional expression incisively and vividly, fully demonstrates the national vocal music singing of the character of the standard of the right tune.

The musical connotations of the characters, such as emotion, image and color, are very delicate, reflecting the inner feelings of the heroine Xier in The White-haired Lady. In vocal music singing, timbre is also very important in the expression of singing language, which is because there are 
specific differences in the position of different singing languages, so we must pay attention to pronunciation and word-biting in singing, so that the melody of the song can develop smoothly. In addition, we also need to pay attention to, through the performance of timbre in the singing language, timbre can give vocal music more artistic expression, only let timbre in the singing language perfect embodiment, the emotions of the song can be expressed incisively and vividly, moving people. For example, in singing the song "I love you, China", we should pay attention to the performance of timbre in the singing language, accurately grasp the pronunciation and attribution, do a good job in dealing with the details of the song minor, sing the charm of the song, better deal with the stress and light tones in the song, and then present a perfect vocal performance for the audience. In vocal music singing, the use of timbre in emotional expression can better help vocalists to convey emotions, move the audience, arouse audience resonance, because timbre is rich in emotions, people express happy or exciting emotions, timbre will become clear and powerful, and in the expression of sadness. The timbre becomes hoarse and dull when the preface is given. Therefore, in vocal music singing, the use of timbre can better express emotional attitude, which is a very common form of expression in vocal music singing. For example, when we sing songs like "Singing the Motherland" or "The Five-Star Red Flag" to praise our motherland, we should use clear and high-pitched tone color to show our praise for our motherland and better convey this positive patriotism to the audience, so as to better express our feelings and move the audience.

\section{The Charm of Love}

Apart from the "charm beauty" of sounds and the "charm beauty" of words, the "charm beauty" of emotion is more prominent, and is also the main form of expression of the "charm beauty" of national vocal music, because the "charm beauty" of emotion is based on the "sound" and "character" charm beauty, and is the first two art forms. Reprocessing creates the core structure of the charm of love. The ultimate goal of national vocal music art is to sublimate emotionally. It is natural and delicate to have a deep feeling. It is emotional to sing affectionately and to infect the audience. Therefore, in order to sing affectionately in the vocal music art, the singer must have affection. Only after understanding thoroughly can he show the emotional color that touches people's hearts in the emotional experience, subtly bring the audience into the artistic conception, and move for the vocal music in the hearing. Of course, in vocal music art, both voice and emotion, in the "word" and "voice" in the charm of "emotion", singers can be the whole song strategy, so that "sound" rhyme, "word" rhyme, "love" rhyme dialectical unity, through the embellishment of the feelings to make more strong national vocal music artistic appeal, create the overall vocal music The charm is beautiful. For example, in the lyrics of the opera "Azalea Mountain: Home in Anyuan", Ke Xiang expresses the restraint of grief at this moment with the word "difficult", "close" adds the feeling of "crying without tears", makes the emotion become strong and implicit, and melodies the tragedy of Peking Opera, so as to melt people into a melody and show them clearly. All the best.

In vocal music singing, different singing styles need to correspond to different timbre, so the specific performance of timbre in singing style is very difficult to control. In the artistic performance, our vocal singers need to integrate into the performance environment and the song atmosphere as soon as possible, and then through their own emotional expression, to the audience to express the emotions, so that the singing style can be assisted by timbre, and then better reflect the style, so that the whole vocal music works appear more. Appeal. For example, in the process of opera singing, vocal singers should have a strong dramatic tone, so as to ensure that the plot ups and downs, better attract the attention of the audience. While singing some national songs, vocal singers should do a good job in adjusting the timbre, so as to ensure the singing mood, better control the 
timbre, reflect the style of the song.

\section{Conclusion}

In a word, Chinese national vocal music shows the beauty of musical charm flexibly in the integration of "character" rhyme, "tone" rhyme and "emotion" rhyme. Although "tone" rhyme and "character" rhyme can fully reflect the "character" with "sound", they are not comprehensive enough, only the "sound" and "character" and "emotion" are integrated and mutually reinforcing. Under the dialectical unity and coordination, the "charm beauty" of the national vocal music art can be embodied so as to show the artistic charm of vocal music singing. To sum up, the use and performance of timbre has a very important impact on the effect of vocal music singing. Therefore, in the process of vocal music singing, we must rationally use timbre, performance timbre, and then convey emotion, so that vocal music singing can give people aesthetic enjoyment.

\section{Acknowledgment}

Fund Project: Heihe University research backbone support project

\section{References}

[1] Li Xiaocheng. Singing art of national vocal music [M]. Hunan literature and Art Publishing House, 2003.

[2] Ding Yi. Perspective of "Sound, Feeling, Character, Taste and Spirit" in Chinese National Vocal Music Singing [J].Chinese Music, 2005, 02:23.

[3] sun LAN Ju. The aesthetic psychology of vocality singing [J]. national music, 2010,03:15-16.

[4] Guo Jie. Analysis of musical aesthetic factors of national vocal music [J]. voice of the Yellow River, 2013,02:13-15.

[5] Shi Xue Gong. How to correctly establish the aesthetic concept of national vocal music art on the [J]. music world, 2017,06:19-21. 